\title{
RANCANG BANGUN TONGKAT BANTU PENDETEKSI PENGHALANG, AIR, DAN LOKASI TUNANETRA
}

\author{
Benny), Ahya Radhiatul Kamila ${ }^{2)}$ dan Teguh Tri Sugiono ${ }^{3)}$ \\ 1,2,3 Jurusan Teknik Elektro, Politeknik Negeri Jakarta, Depok 16425, Indonesia \\ E-mail:를nnypnj@gmail.com, ${ }^{3}$ gtrisugiono@gmail.com
}

\begin{abstract}
Visually impaired is a general term used for the condition of someone who is experiencing a disorder / obstacle in his sense of sight. Barriers that are often experienced by blind people are to determine the object infront of him, puddles, and location. Blind people's obstacles in determining their location caused their family's anxiety. For now, the obstacles experienced by blind people when in public places have not been fully resolved. This tool is made to help the visually impaired (stick users) in order to know the presence of obstructions, puddles, and nlind people's location. For this purpose, the stick is installed with a Soil Moisture Sensor as a water detector, SRF04 Ultrasonic Sensor as a barrier detector, and a GPS tracker as a location detector. This blind assistive stick is equipped with a Limit Switch which is useful as a power saver for barrier and water detection systems. When the auxiliary stick is not being used, the limit switch will not get the pressure from the stick will be OFF.

Keywords: GPS Tracker, Limit Switch, ATMega328, Modul Sim800I, Blind People, SRF04, Soil Moisture Sensor
\end{abstract}

\begin{abstract}
ABSTRAK
Tunanetra adalah istilah umum yang digunakan untuk kondisi seseorang yang mengalami gangguan/hambatan dalam indra penglihatannya.. Hambatan yang sering dialami tunanetra diantaranya adalah hambatan dalam menentukan keberadaan penghalang, genangan air, dan lokasi. Hambatan tunanetra dalam menentukan lokasi menimbulkan kekhawatiran bagi keluarga tunanetra dalam mengetahui keberadaannya. Untuk saat ini, hambatan yang dialami oleh tunanetra ketika berada di tempat umum belum seluruhnya dapat terselesaikan. Alat ini dibuat untuk membantu tunanetra (pengguna tongkat) agar dapat mengetahui keberadaan penghalang, air, dan lokasi tunanetra. Untuk tujuan tersebut maka pada tongkat dipasang Soil Moisture Sensor sebagai pendeteksi air, Sensor Ultrasonik SRF04 sebagai pendeteksi penghalang, dan GPS tracker sebagai pendeteksi lokasi. Tongkat bantu tunanetra ini juga dilengkapi dengan Limit Switch yang berguna sebagai penghemat daya sistem pendeteksi penghalang dan air. Ketika tongkat bantu tidak sedang digunakan, limit switch tidak akan mendapat tekanan sehingga daya dari tongkat akan berada pada kondisi OFF.
\end{abstract}

Kata kunci : GPS Tracker, Limit Switch, ATMega328, Modul Sim8001, Tunanetra, , SRF04, Soil Moisture Sensor

\section{PENDAHULUAN}

Menurut UU No.19 Tahun 2011 tentang pengesahan convention on the rights of persons with disabilities (konvensi mengenai hak-hak penyandang disabilitas), Negara Republik Indonesia adalah negara yang berdasarkan Pancasila dan Undang-Undang Dasar Negara Republik Indonesia Tahun 1945 yang menghormati dan menjunjung tinggi harkat dan martabat manusia sehingga perlindungan dan pemajuan hak asasi manusia terhadap kelompok rentan khususnya penyandang disabilitas perlu ditingkatkan Untuk memenuhi hal tersebut maka diperlukan alat bantu bagi penyandang disabilitas (khususnya tunanetra) untuk melindungi atau membantu mereka dalam menjalani aktivitas. Salah satu langkah yang dapat dilakukan adalah menyediakan alat bantu berupa tongkat bantu tunanetra. Tongkat bantu tunanetra menggunakan sensor ultrasonic SRF04, soil moisture sensor, dan GPS U-Blox Neo M8N.

Permasalahan tunanetra dalam mengidentifikasi penghalang dan air dapat diatasi dengan tongkat bantu tunanetra yang dapat mendeteksi 
penghalang dan air.Tongkat bantu tunanetra disertai dengan sensor SRF04 untuk mendeteksi penghalang, soil moisture sensor untuk mendeteksi air, dan earphone sebagai indikator suara dari keberadaan penghalang dan air. Kehawatiran keluarga/kerabat tunanetra juga menjadi salah satu permasalahan yang dialami tunanetra. Permasalahan ini dapat diatasi dengan tongkat bantu tunanetra yang dapat mendeteksi lokasi tunanetra dan

mengirimkannya ke kerabat tunanetra disertai dengan GPS U-Blox M8N untuk mendeteksi lokasi dan Modul GSM untuk mengirimkan SMS kepada kerabat tunanetra. Tongkat bantu tunanetra diharapkan dapat memudahkan tunanetra dalam mengidentifikasi penghalang dan air, tongkat ini juga diharapkan dapat membantu keluarga tunanetra untuk mengetahui lokasi tunanetra

\section{METODE PENELITIAN}

Pada penulisan laporan ini penulis mengggunakan metode penulisan sebagai berikut : untuk memperoleh teori-teori dasar serta teori penunjang, penulis melakukan pencarian dari berbagai sumber baik dari buku-buku, literatur maupun makalah yan didapat dari perpustakaan dan internet.

Metode perencanaan dan pembuatan alat dilakukan langkah-langkah sebagai berikut: melaksanakan percobaan alat atau rangkaian sesuai dengan data-data yang telah diperoleh dan spesifikasi alat yang diinginkan, melaksanakan perencanaan tiap-tiap blok diagram seperti yang ditunjukan pada Gambar 1.

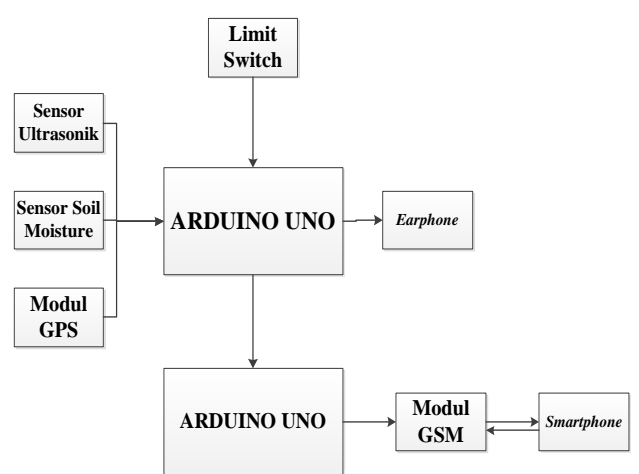

Gambar 1. Diagram Blok Sistem Pendeteksi Penghalang dan Air Tongkat Bantu Tunanetra Cara kerja Tongkat bantu pendeteksi penghalang, air, dan lokasi tunanetra yaitu diawali dengan tunanetra yang menekan limit switch. Posisi limit switch diletakan di pegangan tongkat agar ketika pengguna tongkat (tunanetra) menggunakan tongkat, limit switch dapat tertekan dengan mudah dan akan berada pada posisi $O N$. Output dari limit switch masuk ke mikrokontroler untuk kemudian menghidupkan sistem deteksi penghalang dan air pada tongkat. Sensor air diletakan pada bagian bawah tongkat agar dapat dengan mudah mendeteksi genangan air atau parit. Sementara sensor jarak diletakan pada bagian atas dan bawah tongkat untuk mendeteksi jarak maksimal $1.5 \mathrm{~m}$ dari penghalang. Ketika penghalang atau genangan air terdeteksi, mikrokontroler akan memproses output dari sensor ultrasonik dan sensor air yang kemudian menjadi input dari earphone agar dapat menghasilkan output berupa suara.

Sensor jarak yang digunakan pada tongkat bantu tunanetra adalah Sensor Ultrasonik SRF04. Sensor ultrasonik merupakan sebuah sensor yang memanfaatkan pancaran gelombang ultrasonik untuk mengukur jarak suatu objek dengan jangkauan 2cm-4m. Sensor ultrasonik ini terdiri dari rangkaian pemancar ultrasonik yang disebut transmitter dan rangkaian penerima ultrasonik yang disebut receiver. Sensor HC-SR04 memiliki 4pin male header yang digunakan untuk 
power supply (5 VDC), trigger, echo, dan ground.

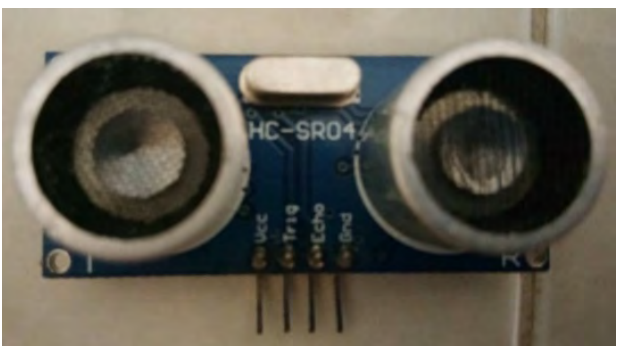

Gambar 2. Sensor Ultrasonik SRF04

Adapun Spesifikasi Sensor Ultrasonik SRF04:

$\begin{array}{ll}\text { Tegangan Kerja } & : 5 \mathrm{~V} \\ \text { Arus Kerja } & : 15 \mathrm{~mA} \\ \text { Frekuensi Kerja } & : 40 \mathrm{~Hz} \\ \text { Maksimum Range } & : 4 \mathrm{~m} \\ \text { Minimum Range } & : 2 \mathrm{~cm} \\ \text { Measuring Angle } & : 15 \\ \text { Trigger Input Signal } & : 10 \mathrm{uS} \text { TTL } \\ \text { Dimensi } & : 45 * 20 * 15 \mathrm{~mm}\end{array}$

Sensor air yang digunakan pada tongkat bantu tunanetra adalah Soil Moisture Sensor. Sensor ini terdiri dari dua probe untuk melewatkan arus melalui tanah dan board PCB yang dilengkapi dengan IC LM393 dan digital potensiometer. Probe pada sensor sudah dilengkapi dengan lapisan kuning pelindung nikel. Sehingga probe pada sensor kelembaban ini dapat terhindar dari oksidasi yang menyebabkan karat. Lapisan ini dinamakan Electroless Nickel immersion Gold (ENIG).

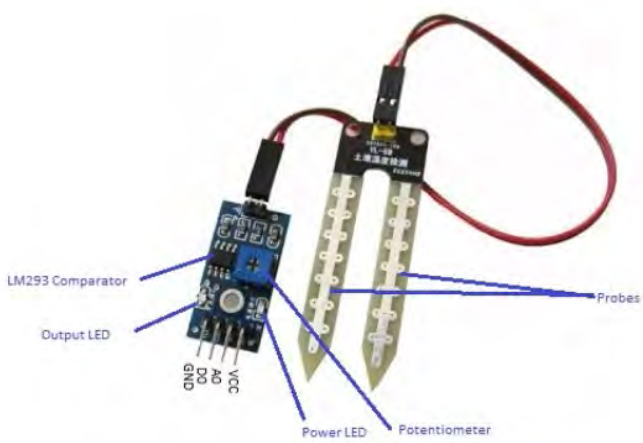

Gambar 3. Soil Moisture Sensor

Adapun spesifikasi sensor soil moisture:

$\begin{array}{ll}\text { VCC Power Supply } & : 3.3 \mathrm{~V} / 5 \mathrm{~V} \\ \text { Arus } & : 35 \mathrm{~mA}\end{array}$

Signal Ouput Voltage : $0-4.2 \mathrm{~V}$

Dimensi Panel

$: 3 \mathrm{~cm} \times 1.6 \mathrm{~cm}$
Dimensi Probe $\quad: 6 \mathrm{~cm} \times 3 \mathrm{~cm}$ Proses pendeteksian lokasi merupakan salah satu bagian penting yang terdapat pada tongkat. Sistem deteksi lokasi pada tongkat bantu tunanetra menggunakan modul GPS Ublox Neo M8N dan Modul GSM Sim 800l. GPS U-Blox Neo M8N membutuhkan tegangan kerja 5 Volt. Menggunakan sistem komunikasi serial dengan baudrate 9600 dengan data yang dikirim berupa data NMEA GGA yang diurai dan didapat berupa data degrees minutes (DM) kemudian dirubah menjadi degree decimal (DD) untuk mendapatkan nilai longitude dan latitude.

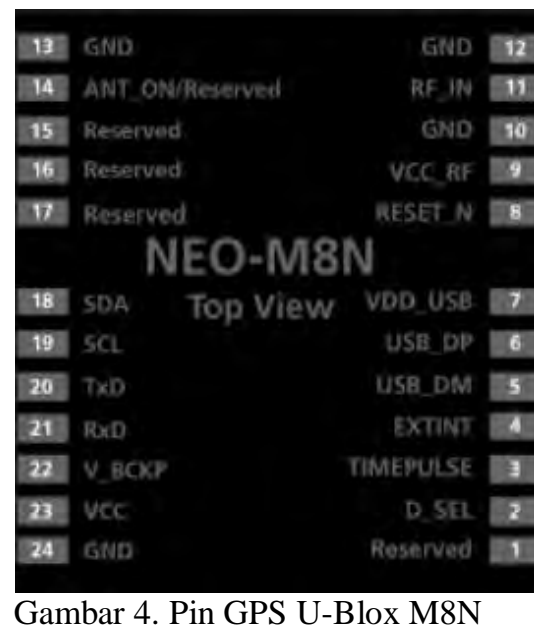

Modul GPS digunakan untuk mendeteksi lokasi berupa nilai latitude dan longitude, sedangkan modul GSM digunakan untuk mengirimkan titik lokasi berupa link yang dapat dilihat melaluiaplikasigoogle maps maupunapli kasi browser lainnya.

Adapun Flowchart dari system deteksi penghalang, air, dan lokasi pada tongkat bantu tunanetra adalah sebagai berikut: 
Benny, Ahya R. K dan Teguh Tri S. Rancang Bangun Tongkat...

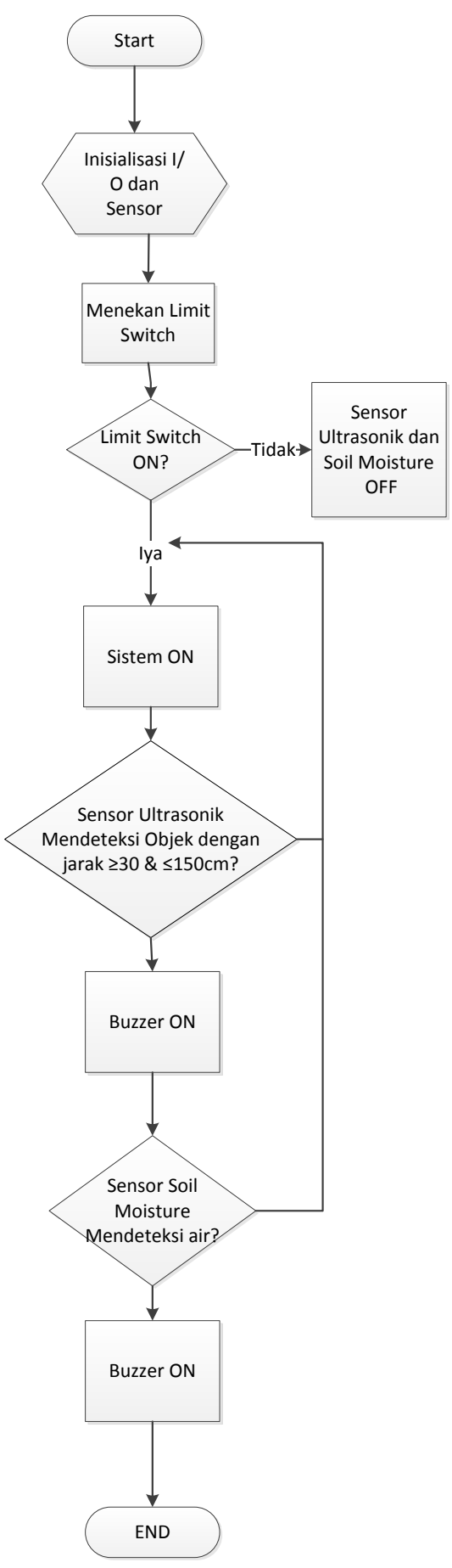

Gambar 5. Diagram Alir Sistem Pendeteksi Penghalang dan Air pad Tongkat Bantu Tunanetra

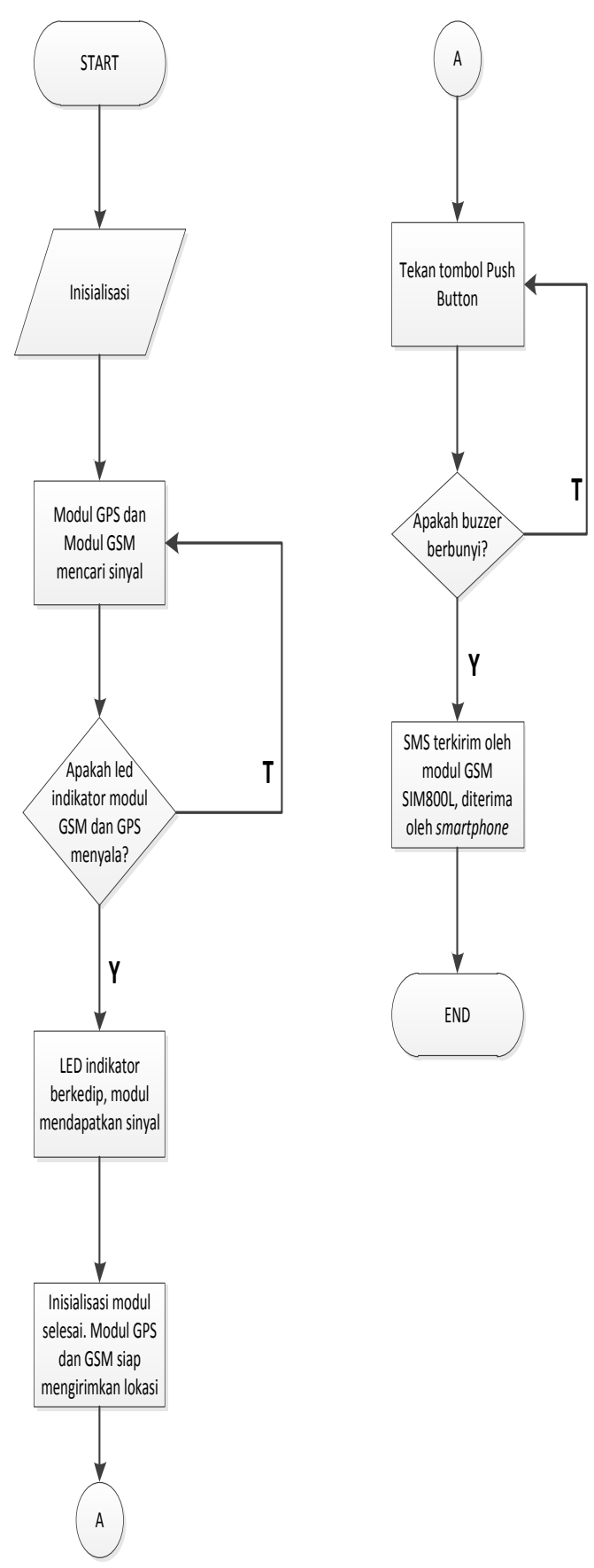

Gambar 6. Diagramalir Sistem Deteksi Lokasi dengan push button sebagai syarat mengirim titik lokasi ke smartphone 
Adapun data hasil pengujian Sensor Ultrasonik, Soil Moisture Sensor, dan GPS GPS Tracker adalah sebagai berikut:

Tabel 1. Data Hasil Pengujian Sensor Ultrasonik

\begin{tabular}{ccc}
\hline No & Waktu(s) & Jarak (cm) \\
\hline 1 & 0.17 & 29 \\
2 & 0.22 & 38 \\
3 & 0.28 & 48 \\
4 & 0.33 & 57 \\
5 & 0.38 & 66 \\
6 & 0.44 & 75 \\
7 & 0.5 & 85 \\
8 & 0.55 & 95 \\
9 & 0.62 & 105 \\
10 & 0.67 & 115 \\
11 & 0.73 & 125 \\
12 & 0.78 & 134 \\
13 & 0.84 & 144 \\
\hline
\end{tabular}

\section{Spesifikasi Alat :}

Gambar 7. Diagram Alir Sistem Deteksi Lokasi dengan pengiriman pesan oleh smartphone sebagai syarat mengirim titik lokasi ke

$$
\text { smartphone }
$$

$\begin{array}{ll}\text { Tegangan Sumber } & : 11.1 \mathrm{~V} \\ \text { Arus Input } & : 300 \mathrm{~mA} \\ \text { Waktu Standby } & : 18 \mathrm{Jam} \\ \text { Dimensi Alat } & :(13 \times 12.4 \times 90) \mathrm{cm} \\ \text { Berat Tongkat } & : 0.73 \mathrm{Kg} \\ \text { Warna Tongkat } & : \text { Hitam } \\ \text { Dimensi Box } & :(13 \times 12.3 \times 4.9) \mathrm{cm}\end{array}$

Pengujian sensor Ultrasonik SRF04 dilakukan dengan mengukur waktu pantul gelombang ulrasonik yang dipancarkan oleh pin trig dan diterima oleh pin echo. Pengujian ultrasonic juga dilakukan dengan meletakan sensor ultrasonic pada jarak tertentu dengan suatu objek sebagai bidang pantul, kemudian penulis mengamati perubahan jarak yang didapatkan melalui serial monitor pada laptop.

Tabel 2 . Data Hasil Pengujian Sensor Soil Moisture

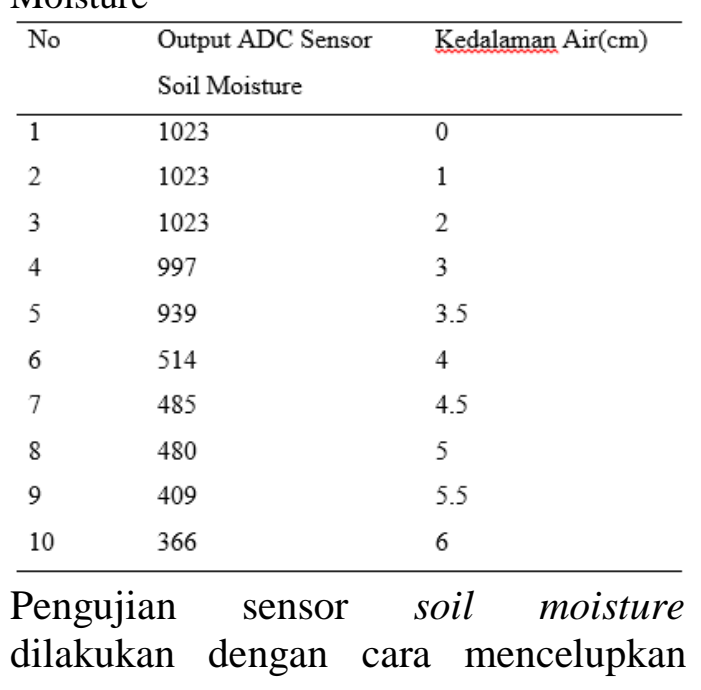


sensor soil moisture ke dalam air. Ketinggian air yang digunakan dalam pengujian sensor ini berbeda-beda agar penulis dapat mengetahui kedalaman air minimal yang dapat dideteksi dan. Hasil pengujian yang didapatkan menunjukan bahwa semakin besar nilai kedalaman air, maka semakin kecil nilai ADC.

Tabel 3. Data Hasil Deteksi Titik Lokasi dan Modul GPS

\begin{tabular}{|l|l|}
\hline Titik lokasi yang Terdeteksi & Selisih Jarak Terukur \\
\hline$-6.372304,106.823814$ & $+-10 \mathrm{~m}$ \\
\hline$-6.372303,106.823814$ & $+-10 \mathrm{~m}$ \\
\hline$-6.372305,106.823806$ & $+-10 \mathrm{~m}$ \\
\hline-6.372304 .106 .823814 & $+-10 \mathrm{~m}$ \\
\hline-6.372305 .106 .823806 & $+-10 \mathrm{~m}$ \\
\hline$-6.372330,106.823783$ & $+-10 \mathrm{~m}$ \\
\hline$-6.372330,106.823783$ & $+-10 \mathrm{~m}$ \\
\hline$-6.372330,106.823783$ & $+-10 \mathrm{~m}$ \\
\hline$-6.372330,106.823783$ & $+-10 \mathrm{~m}$ \\
\hline$-6.372330,106.823783$ & $+-10 \mathrm{~m}$ \\
\hline$-6.372330,106.823783$ & $+-10 \mathrm{~m}$ \\
\hline$-6.372330,106.823783$ & $+-10 \mathrm{~m}$ \\
\hline$-6.372344,106.823745$ & $+-10 \mathrm{~m}$ \\
\hline$-6.372344,106.823745$ & $+-10 \mathrm{~m}$ \\
\hline$-6.372344,106.823738$ & $+-10 \mathrm{~m}$ \\
\hline$-6.372344,106.823738$ & $+-10 \mathrm{~m}$ \\
\hline
\end{tabular}

Tabel hasil pengukuran lokasi oleh modul gps menunjukkan adanya perbedaan nilai hasil deteksi oleh modul gps. Perbedaan jarak yang terdeteksi dengan jarak yang sebenarnya tidak terlalu jauh. Penentuan jumlah nilai yang akan ditampilkan setelah modul mendeteksi lokasi pun akan berpengaruh pada tingkat ke akurasian titik lokasi yang terdeteksi.

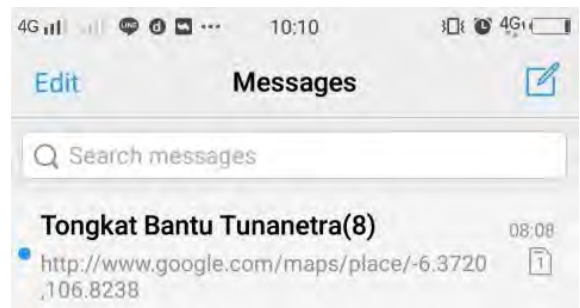

Gambar 8 Pesan Titik Lokasi Hasil Pengukuran GPS Tracker

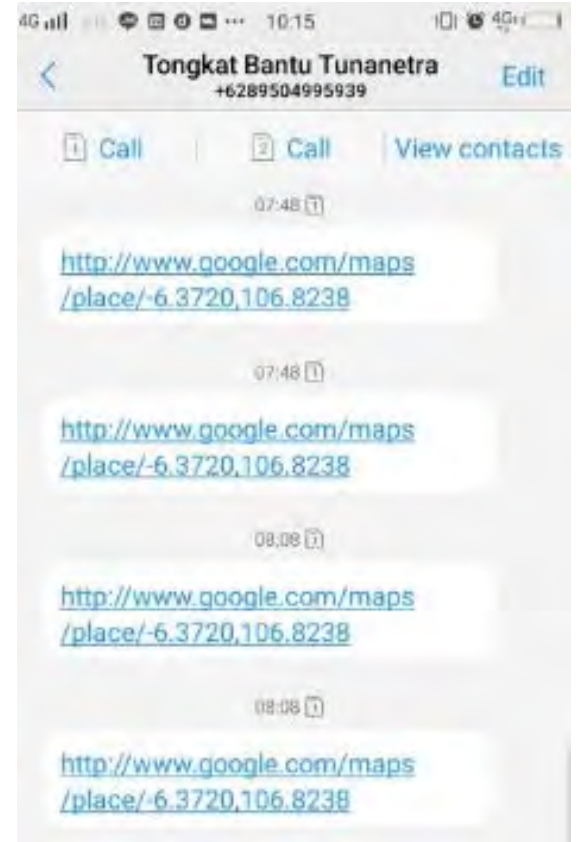

Gambar 9. Isi Pesan Link.Lokasi

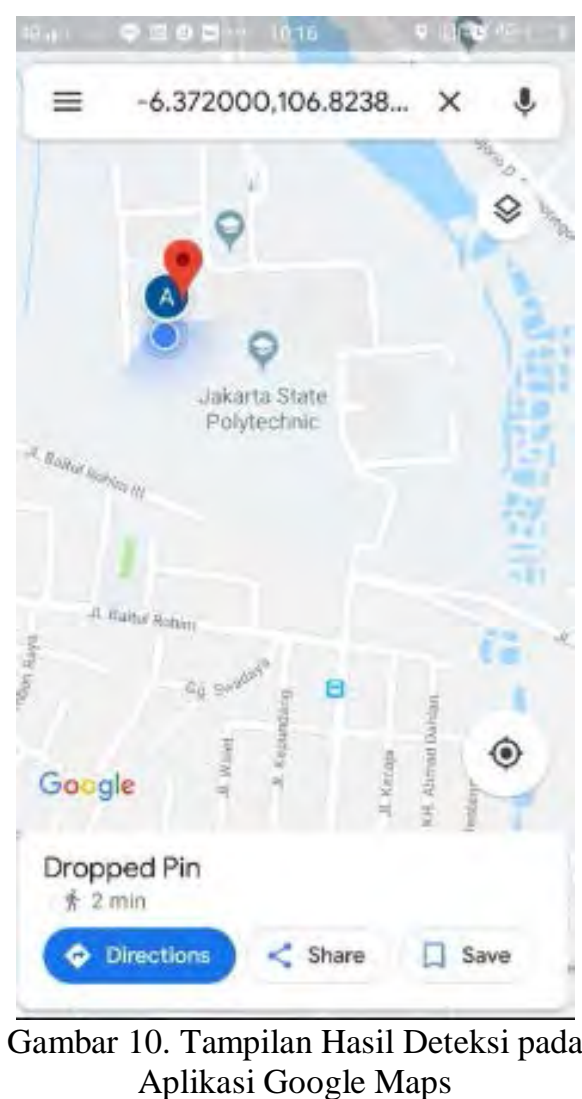
Aplikasi Google Maps 


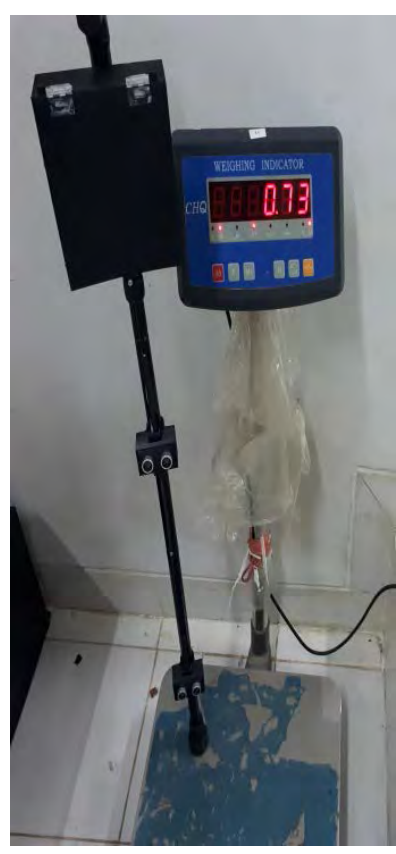

Gambar 11. Tongkat Bantu Pendeteksi Penghalang, Air, dan Lokasi Tunanetra

\section{KESIMPULAN}

Dari pembuatan tongkat bantu tunanetra dapat ditarik beberapa kesimpulan, yaitu : 1) Tongkat bantu tunanetra dilengkapi dengan limit switch yang berfungsi sebagai saklar ON/OFF. Output dari limit switch masuk ke mikrokontroler untuk kemudian menghidupkan sistem deteksi penghalang dan air pada tongkat. Ketika penghalang atau genangan air terdeteksi, mikrokontroler akan memproses output dari sensor ultrasonik dan sensor air yang kemudian menjadi input dari earphone agar dapat menghasilkan output berupa suara. Tongkat bantu tunanetra juga dilengkapi dengan GPS U-Blox M8N. modul gps dan modul gsm mencari sinyal yang digunakan untuk menentukan titik lokasi serta menerima dan mengirimkan pesan ke smartphone. Modul gps \& modul gsm yang telah mendapatkan sinyal ditandai dengan led yang ada pada modul berkedip. 2) Pemograman sistem deteksi penghalang, air, dan lokasi pada tongkat bantu tunanetra dilakukan pada software Arduino IDE. Sebelum membuat program pada software Arduino IDE, penulis membuat flowchart yang digunakan untuk menggambarkan, menyederhanakan rangkaian proses atau prosedur sehingga mudah dipahami dan mudah dilihat berdasarkan urutan langkah dari suatu proses.

\section{DAFTAR PUSTAKA}

[1] Afif, Muhammad, Thowil dan Pratiwi, Ilham Ayu Putri. 2015. "Analisis Perbandingan Baterai Lithium-Ion, Lithium-Polymer, Lead Acid dan Nickel-Metal Hydrine pada Penggunaan Mobil Listrik-Review”. Jurnal Rekayasa Mesin. Malang

[2] Lomo, Lika Abraham. 2016. "Smart Green House Berbasis Mikrokontroler Arduino Mega2560 REV3”. Tugas Akhir S1 Teknik Elektro. Yogyakarta

[3] Pratama, Dendy. dkk. 2016. "Rancang Bangun Alat dan Aplikasi untuk para Penyandang Tunanetra Berbasis Smartphone Android”. Jurnal Ilmu Komputer dan Informatika

[4] Sulistyanto, Prayadi. 2013. "Syringe Pump Otomatis Berbasis Mikrokontroler Arduino Uno". Tugas Akhir S1 Teknik Elektro. Yogyakarta

[5] Syam, Rafiuddin. 2013. "DasarDasar Teknik Sensor”. Buku Ajar Fakultas Teknik Universitas Hasanuddin. Makassar

[6] Saleh, Muhammad dan Haryanti, Munnik. 2017. "Rancang Bangun Sistem Keamanan Rumah Menggunakan Rela. Jurnal Teknologi Elektro. Jakarta 
Benny, Ahya R. K dan Teguh Tri S. Rancang Bangun Tongkat... 